\title{
Therapeutic Equivalence of a New Preparation of Liquid Levothyroxine with Tablets in Patients with Overt Primary Hypothyroidism
}

\author{
Georgios K. Markantes ${ }^{a}$ Konstantinos Dimitropoulos ${ }^{a} \quad$ Irene Mamali $^{\mathrm{a}}$ \\ Ioulia Tseti $^{\mathrm{b}}$ George Sakellaropoulos ${ }^{c}$ Kostas B. Markou ${ }^{\mathrm{a}}$ Marina A. Michalaki ${ }^{\mathrm{a}}$ \\ ${ }^{a}$ Division of Endocrinology, Department of Internal Medicine, University of Patras Medical School, Patras, Greece; \\ ${ }^{b}$ Uni-Pharma S.A., Athens, Greece; ' ${ }^{C}$ Department of Medical Physics, School of Medicine, University of Patras, \\ Patras, Greece
}

\section{Keywords}

Therapeutic equivalence · Levothyroxine · Liquid levothyroxine $\cdot$ Hypothyroidism $\cdot$ TSH

\begin{abstract}
Background: A new liquid levothyroxine (LT4) dissolved in glycerol and water has recently been developed by a Greek pharmaceutical company (Uni-Pharma, Athens, Greece). Objectives: To evaluate the therapeutic equivalence of this new liquid LT4 preparation versus the already existing tablet formulation of the same manufacturer, in order to obtain approval by the Greek National Organization for Medicines. Methods: This was a prospective, randomized, cross-over phase III study. The study included 50 patients ( 9 men and 41 non-pregnant women, with a mean age of $42.5 \pm 12.5$ years), with documented overt primary hypothyroidism. All subjects were well controlled on substitution therapy with various LT4 formulations. None of the patients had known LT4 malabsorption. The patients were randomized into 2 groups ( $A$ and $B$ ). The individuals of group $A$ initially received $\mathrm{T} 4^{\circledR}$ tablets for $10 \pm 2$ weeks and subsequently switched to $\mathrm{T} 4^{\circledR}$ drops (100 $\mu \mathrm{g} / \mathrm{mL}$ solution) at the same dose for another $10 \pm 2$ weeks. In group B, the reverse procedure was followed. Total T3 (T3), free T4 (fT4), and TSH were measured in
\end{abstract}

karger@karger.com www.karger.com/etj

(c) 2020 European Thyroid Association Published by S. Karger AG, Basel all participants at enrollment and at the end of each $10 \pm$ 2-week trial period. Results: Out of the 50 recruited patients, 6 were lost to follow-up and 5 were excluded due to noncompliance with the study protocol. In the 39 patients who completed the study, the serum TSH levels after $10 \pm 2$ weeks of treatment either with $\mathrm{T} 4{ }^{\circledR}$ tablets or with $\mathrm{T} 44^{\circledR}$ drops did not differ ( $1.759 \pm 1.104$ vs. $2.076 \pm 1.334 \mathrm{mIU} / \mathrm{L}$, mean \pm SD). Conclusions: In hypothyroid patients, the new liquid LT4 preparation ( $\mathrm{T} 4{ }^{\circledR}$ drops) is therapeutically equivalent to the tablet form $\left(\mathrm{T} 4{ }^{\circledR}\right.$ tablets).

(c) 2020 European Thyroid Association Published by S. Karger AG, Basel

\section{Introduction}

Hypothyroidism is a very common disease. The prevalence of overt hypothyroidism in the general population ranges from 0.2 to $5.3 \%$ in Europe and from 0.3 to $3.7 \%$ in the USA, depending on the definition used and population studied [1]. Levothyroxine (LT4) monotherapy is the standard of care in hypothyroidism, and the goal of treatment is the normalization of serum TSH levels [2].

Nowadays, several different LT4 formulations are available on the market; tablets, soft gel capsules, and liquid forms, generic or brand name, which could differ in 
bioavailability, but are all acceptable for the treatment of hypothyroidism. Hence, maintenance of the same formulation of LT4 (brand name or generic) in every patient treated for hypothyroidism is advised by the American Thyroid Association (ATA) and the American Association of Clinical Endocrinologists (AACE) [2,3].

LT4 tablets are dissolved in the acidic environment of the stomach, and then absorption takes place at the jejunum and upper ileum. The proportion of an orally administered dose that is absorbed ranges from 42 to $80 \%$, depending on the LT4 formulation as well as the fasting state [4]. Numerous factors may affect LT4 absorption. Intestinal diseases (such as celiac disease, Helicobacter pylori infection, atrophic gastritis, etc.), fiber-rich food and coadministered medication (e.g., iron, calcium, proton pump inhibitors) reduce its absorption [5], whereas fasting increases it [4]. A liquid formulation already existing on the market, which contains LT4 dissolved in glycerol and ethanol has been shown to resolve problems of tablet LT4 malabsorption caused, for example, by coadministration of calcium and iron salts [6] or multiple interfering drugs [7].

A new preparation of liquid LT4 dissolved in glycerol and water $\left(\mathrm{T} 4{ }^{\circledR} 100 \mu \mathrm{g} / \mathrm{mL}\right.$ oral drops, solution; UniPharma, Athens, Greece) has recently become available, aspiring to get established as a reliable LT4 formulation, as well as to deal with the problems of malabsorption and swallowing difficulties of the tablet formulation of LT4. In the present study, we examine the clinical equivalence of this new preparation ( $\mathrm{T} 4{ }^{\circledR}$ drops, liquid form), for which approval by the Greek National Organization for Medicines is pending, with the tablet formulation of the same manufacturer (T4 ${ }^{\circledR}$ tablets; Uni-Pharma).

\section{Materials and Methods}

\section{Patients}

We recruited 50 patients aged between 20 and 60 years with well-documented overt primary hypothyroidism (42 with Hashimoto's thyroiditis present for $>3$ years and 8 patients thyroidectomized for toxic/nontoxic multinodular goiter), well controlled on substitution therapy with any LT4 preparation. At enrollment, 34 patients were on $\mathrm{T} 4{ }^{\circledR}$ tablets (Uni-Pharma), 10 patients on Thyrohormone ${ }^{\circledR}$ tablets (NI-THE, Greece), 4 patients on Euthyrox ${ }^{\circledR}$ tablets (Merck, Germany), 1 patient on Medithyrox ${ }^{\circledR}$ tablets (Intermed, Greece), and 1 patient on Tirosint ${ }^{\circledR}$ soft capsules (IBSA Farmaceutici, Italy). Subjects with any cardiac disease (e.g., arrhythmia, coronary artery disease, etc.), any gastrointestinal disorder potentially affecting LT4 absorption (celiac disease, $H$. pylori infection, atrophic gastritis, etc.), thyroid cancer, those taking any medication interfering with LT4 absorption or metabolism, and pregnant women, were excluded from the study.
Table 1. Composition of the liquid and tablet LT4 formulation

\begin{tabular}{ll}
\hline Liquid LT4 $\left(T 4^{\circledR}\right.$ drops) & Quantity (per 1 mL) \\
Ingredient & \\
Active ingredients & \\
$\quad$ Levothyroxine sodium anhydrous & $100 \mu \mathrm{g}$ \\
Excipients & \\
$\quad$ Glycerol 99.5\% w/w & \\
$\quad$ Trisodium citrate (as dihydrate) & \\
$\quad \mathrm{NaOH}(1 \mathrm{M})$ & \\
$\quad$ Purified water & Quantity (per tablet) \\
\hline Tablet LT4 (T4 ${ }^{\circledR}$ tablets) & Depending on tablet strength \\
Ingredient & \\
Active ingredients & \\
$\quad$ Levothyroxine sodium & \\
Excipients & \\
$\quad$ Lactose monohydrate & \\
Sodium starch glycolate & \\
Cellulose microcrystalline & \\
Silicon dioxide colloidal & \\
Magnesium stearate & \\
Colorants &
\end{tabular}

\section{Study Design}

This was a prospective, randomized, cross-over phase III study in subjects with pre-existing overt hypothyroidism. After enrollment, study participants were randomized in 2 groups (A and B). The participants in group $\mathrm{A}(n=25)$ initially received $\mathrm{T} 4{ }^{\circledR}$ tablets for $10 \pm 2$ weeks and subsequently switched to $T 4^{\circledR}$ drops at the same dose for another $10 \pm 2$ weeks, while in those of group $\mathrm{B}(n=25)$, the reverse procedure was followed. Each patient had 3 scheduled visits (and, if necessary, 1 additional visit for dose titration purposes - see below) at $10 \pm 2$ weeks intervals (Fig. 1). Physical examination, assessment of the patient's adherence to the treatment, safety assessment and blood sampling in the morning for determination of serum TSH, T3, and fT4 were conducted at each visit. Patients were advised to receive each LT4 formulation with one glass of water after an overnight fast and to have breakfast at least $30 \mathrm{~min}$ thereafter. They were also instructed not to take their LT4 preparation before blood sampling on the scheduled visits for thyroid hormone measurements. We set the therapeutic target range of TSH levels at $0.45-$ $4.12 \mathrm{mIU} / \mathrm{L}$ [8], since Greece is an iodine sufficient country [9]. At enrollment, the patients were provided with diaries for the daily recording of the type and dose of the LT4 preparation administered at each stage of the study, in order to ensure their adherence to the protocol. At enrollment in the study (first visit), the LT4 preparation that the patient was receiving prior to entering the study was switched either to $\mathrm{T} 4{ }^{\circledR}$ tablets (group A) or $\mathrm{T} 4{ }^{\circledR}$ drops (group B), in the same dose (Fig. 1). At the second visit, if the TSH levels were within the target range, the patient was switched from the tablet to the liquid form with the same dose and vice versa. If not, dose adjustment of the current LT4 preparation was performed and an additional visit was scheduled. At the additional visit, if TSH remained out of the target range, the patient was excluded from the study, whereas if TSH levels normalized, the patient was switched to the alternative formulation of LT4 at the same dose. The inclusion of
60

Eur Thyroid J 2021;10:59-64 DOI: $10.1159 / 000508216$
Markantes et al. 


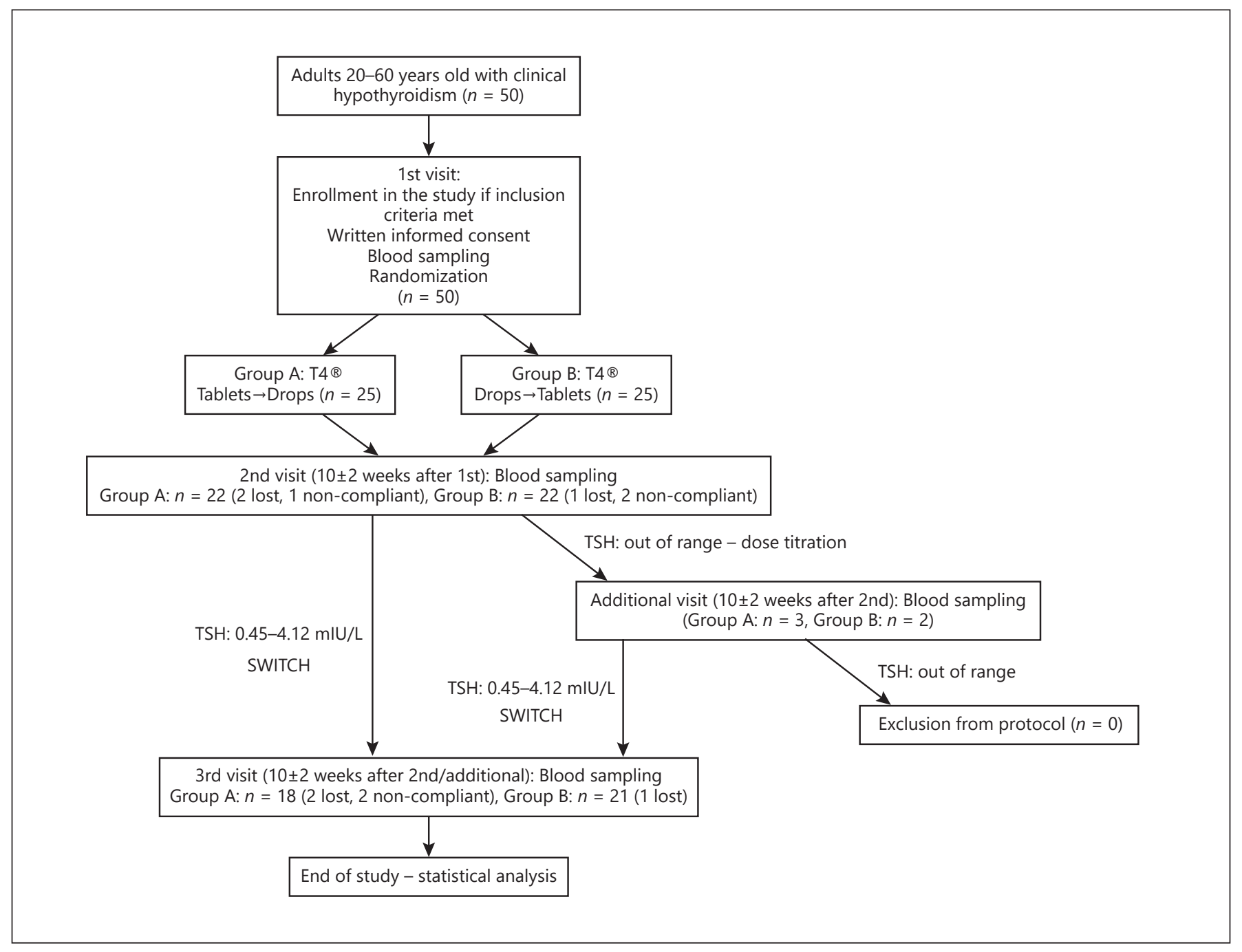

Fig. 1. Study flowchart.

this extra visit was considered necessary due to the possible differences in bioequivalence among different LT4 formulations. At the last visit, physical examination and blood sampling were performed and the study was concluded. Serum was collected from all blood samples and was immediately stored at $-20^{\circ} \mathrm{C}$ until analysis. All samples were assayed within one run.

Composition of the Liquid (T4 ${ }^{\circledR}$ Drops) and Tablet $\left(T 4^{\circledR}\right.$ Tablets) LT4 Formulations

The liquid and tablet LT4 formulation used in our study were manufactured by Uni-Pharma S.A. The composition of each LT4 preparation is shown in Table 1. In the liquid formulation, LT4 is dissolved in glycerol and purified water. It is a colorless, odorless, slightly viscous solution of $100 \mu \mathrm{g} / \mathrm{mL}$ concentration, available in a $30 \mathrm{~mL}$ bottle with a built-in dosimetry dropper device. The proposed lifespan of the product is 18 months, and it is well-preserved at room temperature for 1 month since opening. Twenty drops of the solution contain $100 \mu \mathrm{g}$ of LT4.

Therapeutic Equivalence of Liquid LT4 with Tablets in Hypothyroid Patients

\section{Thyroid Hormone Measurements}

All assays for hormone determinations were performed by electrochemiluminescence quantitation (Elecsys 2010; Roche Diagnostics, Laval, QC, Quebec) in the Endocrinology Laboratory of the University Hospital of Patras. The intra-run and inter-run coefficient of variance values were $1.1-3.0 \%$ and $3.2-7.2 \%$ for TSH, 1.5-3.1\% and 3.4-4.5\% for T3, and $1.6-5.0 \%$ and $2.1-6.3 \%$ for $\mathrm{PT} 4$, respectively. The lower limits of detection were $0.005 \mathrm{mIU} / \mathrm{L}$ for $\mathrm{TSH}, 0.195 \mathrm{ng} / \mathrm{mL}$ for T3, and $0.023 \mathrm{ng} / \mathrm{dL}$ for $\mathrm{fT} 4$. The normal range for each of the parameters studied was as follows: TSH: 0.45$4.12 \mathrm{mIU} / \mathrm{L}, \mathrm{T} 3: 0.8-2.0 \mathrm{ng} / \mathrm{mL}$, and fT4: 0.8-2.0 ng/dL.

\section{Statistical Analysis}

Data are presented as mean \pm SD. Normality was tested with the Kolmogorov-Smirnov test. Comparisons were made using the independent and the paired-sample Student $t$ test, Mann-Whitney $\mathrm{U}$ test, $\chi^{2}$ test, and Wilcoxon signed-rank test, as appropriate. The significance level was set at 0.05 . 
Table 2. Baseline characteristics of the patients in groups A and $B$

\begin{tabular}{lccl}
\hline & Group A & Group B & $\begin{array}{l}p \\
\text { value }\end{array}$ \\
\hline Age, years & $45.72 \pm 12.03$ & $39.20 \pm 12.30$ & $\mathrm{~ns}$ \\
Sex, F/M & $21 / 4$ & $20 / 5$ & $\mathrm{~ns}$ \\
$\mathrm{BMI}, \mathrm{kg} / \mathrm{m}^{2}$ & $25.42 \pm 4.63$ & $27.25 \pm 5.60$ & $\mathrm{~ns}$ \\
$\mathrm{TSH}, \mathrm{mIU} / \mathrm{L}$ & $2.006 \pm 1.133$ & $1.727 \pm 0.816$ & $\mathrm{~ns}$ \\
$\mathrm{fT} 4, \mathrm{ng} / \mathrm{dL}$ & $1.515 \pm 0.219$ & $1.480 \pm 0.181$ & $\mathrm{~ns}$ \\
$\mathrm{~T} 3, \mathrm{ng} / \mathrm{mL}$ & $1.056 \pm 0.187$ & $1.002 \pm 0.202$ & $\mathrm{~ns}$ \\
LT4 dose at enrollment, $\mu \mathrm{g} / \mathrm{kg}$ & $1.40 \pm 0.33$ & $1.38 \pm 0.39$ & $\mathrm{~ns}$ \\
\hline
\end{tabular}

Data are expressed as mean $\pm \mathrm{SD}$. The independent samples $t$ test was used for all comparisons except for BMI, where the MannWhitney test was used (non-normally distributed data) and for sex, where the $\chi^{2}$ test was used.

Table 3. TSH, T3, and fT4 in the 39 patients who completed the study, while receiving tablets or oral drops

\begin{tabular}{llll}
\hline & T4 $^{\circledR}$ tablets & T4 $^{\circledR}$ drops & p value \\
\hline TSH, mIU/L & $1.759 \pm 1.104$ & $2.076 \pm 1.334$ & ns \\
T3, ng/mL & $0.985 \pm 0.185$ & $0.998 \pm 0.181$ & ns \\
fT4, $\mathrm{ng} / \mathrm{dL}$ & $1.448 \pm 0.232$ & $1.363 \pm 0.216$ & 0.008 \\
\hline
\end{tabular}

Data are expressed as mean \pm SD. The paired samples $t$ test was used for comparisons regarding TSH and T3, whereas the Wilcoxon signed-rank test was used for fT4 (non-normally distributed data).

\section{Results}

There was no difference in the baseline characteristics (age, sex, BMI, TSH, fT4, T3, LT4 replacement dose) of the patients of group A versus those of group B (Table 2).

Out of the 50 recruited patients ( 9 men and 41 women with a mean age of $42.5 \pm 12.5$ years), 6 were lost to followup and 5 were excluded due to non-compliance with the study protocol. Four out of the 5 non-compliant patients were under treatment with drops at that time, and noncompliance was related to difficulties in counting the drops corresponding to their LT4 dose. Hence, 39 patients ( 7 men and 32 women) completed the study: 32 with Hashimoto's thyroiditis and 7 with a history of total thyroidectomy. At the second visit, 5 patients out of 39 (all of whom were receiving LT4 preparations other than $\mathrm{T} 4{ }^{\circledR}$ at the study entry) had serum TSH levels out of the target range, so adjustment of the dose was performed, and an additional visit was required. In all of them, TSH normalized at the extra visit (Fig. 1).
No statistically significant difference was noted regarding the mean levels of serum TSH and T3 after treatment with the same dose of either $\mathrm{T} 4{ }^{\circledR}$ drops or $\mathrm{T} 44^{\circledR}$ tablets (Table 3$)$. However, serum fT4 was slightly (5.88\%) lower after treatment with $\mathrm{T} 4{ }^{\circledR}$ drops compared to $\mathrm{T} 4{ }^{\circledR}$ tablets (Table 3). No adverse effects or incidents were reported during treatment with either $\mathrm{T} 4{ }^{\circledR}$ tablets or $\mathrm{T} 4{ }^{\circledR}$ drops, and none of the patients exhibited symptoms of hypothyroidism.

\section{Discussion}

Our results showed that a new preparation of liquid LT4 (T4 ${ }^{\circledR}$ drops) dissolved in glycerol and water is therapeutically equivalent to the pre-existing tablet preparation (T4 ${ }^{\circledR}$ tablets) of the same manufacturer in patients with overt hypothyroidism and without known LT4 malabsorption.

We evaluated the equivalence of this new liquid formulation in hypothyroid patients, by measuring serum TSH levels after $10 \pm 2$ weeks of treatment with each LT4 formulation. According to the guidelines of the AACE and ATA for hypothyroidism, serum TSH levels need approximately 8 weeks to plateau after dosage adjustments or changes between LT4 preparations in hypothyroid patients [8]. We did not choose to evaluate the bioequivalence of the 2 preparations with a pharmacokinetic study [10], because such studies have been criticized by several scientific associations due to the following weaknesses. First, the pharmacologic dose of $600 \mu \mathrm{g}$ of LT4 is considerably higher than the "physiologic" doses used in clinical practice and similar kinetics cannot be assumed. Furthermore, pharmacokinetic studies have been proven unable to distinguish LT4 dosing strengths differing by up to $12.5 \%$, even if mathematical correction methods are applied. Finally, such pharmacokinetic studies do not take into account the TSH levels $[2,3]$. TSH is secreted by the pituitary gland and it is considered the most accurate and sensitive biomarker to assess the adequacy of LT4 replacement therapy (gold standard) over the last 30 years, as it reflects the tissue response to the administered LT4 [11].

In our study, serum TSH levels were similar in hypothyroid patients when they received the same dose of LT4, either as $\mathrm{T} 4{ }^{\circledR}$ tablets or as $\mathrm{T} 4{ }^{\circledR}$ drops, a finding suggestive of therapeutic equivalence of the 2 formulations. Serum T3 levels were found to be at the lower limit of the normal range and similar in both LT4 formulations. Serum fT4 levels were slightly lower after substitution with
Markantes et al. 
$\mathrm{T} 44^{\circledR}$ drops compared to $\mathrm{T} 4{ }^{\circledR}$ tablets. Few studies in the literature have examined serum levels of thyroid hormones after liquid LT4 administration. In 3 of them [1214], serum fT4 levels were comparable after treatment with either tablet or liquid LT4, even if liquid LT4 was taken with breakfast $[13,14]$. In other studies, the use of a liquid preparation of LT4 has been associated with increased fT4 levels $[15,16]$ and lower TSH [16]. In our study, the finding of slightly lower fT4 levels when patients received oral drops while TSH levels were similar with either therapy appears to be paradoxical. However, this difference of $\sim 5 \%$ in $\mathrm{fT} 4$ may not have physiological significance.

Data retrieved from the NHANES study from the years 2001-2012 have shown that in LT4-treated participants serum free and total T4 were about $10 \%$ higher in those with lower serum TSH levels (TSH 0.24-1.74 vs. $1.75-5.40 \mathrm{mIU} / \mathrm{L}$ ), whereas serum total and free T3 levels were similar and at the lower end of the normal range in both groups [17]. In another study using simulated thyroidectomized patients, a 25\% drop in administered LT4 potency resulted in an increase of TSH from 1.5 to 6 $\mathrm{mIU} / \mathrm{L}$ and a $14 \%$ drop of serum T4 [18]. It is known that there is a fine-tuned negative feedback regulation of the hypothalamic-pituitary-thyroid (HPT) axis [19]. Recent large population studies have shown that the TSH-fT4 relationship is complex and that the best fitted model for TSH-fT4 depends on the individual HPT axis set point, age, sex, and thyroid function status [20-22]. Hadlow et al. [20] found that in LT4-treated hypothyroid patients, the TSH response to fT4 alterations is attenuated (as evidenced by a lesser slope in the TSH-fT4 curves) when fT4 values are within the reference range. Hence, it is difficult to estimate the minimal required change in serum fT4 levels that would effectively alter serum TSH levels. We hypothesize that this slight difference in serum fT4 levels between $\mathrm{T} 4^{\circledR}$ drops and $\mathrm{T} 4{ }^{\circledR}$ tablets observed in our study was not enough to alter TSH secretion appreciably.

Nowadays, liquid formulations of LT4 have gained popularity in the treatment of hypothyroidism, especially in cases of treatment-refractory hypothyroidism [23]. Several studies have proven that liquid formulations or soft gel capsules of LT4 are more efficient in patients with LT4 malabsorption [24]. The absence of lactose, citric acid, and corn starch from the excipients of liquid and soft gel LT4 formulations makes them more appropriate in patients with food allergies [25]. Certain liquid LT4 preparations contain small amounts of ethanol as an excipient (e.g., one unit-dose ampoule containing $243 \mathrm{mg}$

Therapeutic Equivalence of Liquid LT4 with Tablets in Hypothyroid Patients ethanol or about $2.4 \mathrm{mg}$ ethanol per $1 \mu \mathrm{g}$ of LT4) and caution is needed when they are prescribed to specific populations, such as pregnant women, newborns, and subjects with liver diseases or alcohol addiction/intolerance [26]. Cassio et al. [27] found that the administration of daily doses of ethanol $>75 \mathrm{mg}$ seemed not to affect growth and psychometric outcomes in neonates treated with liquid LT4 for congenital hypothyroidism. However, surrogate markers of liver function were not measured in that study and the authors advise careful monitoring for possible adverse effects related to long-term ethanol exposure. In adults, a recently published study [25] has examined the possible effect of alcohol contained in liquid LT4 formulations on the control of hypothyroidism. A questionnaire was designed to aid clinicians to select the most appropriate LT4 formulation in hypothyroid patients by screening for gastrointestinal diseases, specific dietary habits, and food allergies. A total of $12 \%$ of the included patients were identified as alcohol intolerant/abstinent/ addicted. Questionnaire-based selection of the administered LT4 formulation led to better TSH control with less dose adjustments and smaller final LT4 dose, compared to history only-based selection [25]. In the liquid formulation used in our study, LT4 is dissolved in glycerol and water instead of ethanol, so it is ideal for patients with a history of alcohol addiction or intolerance, as well as for teetotalers and children.

A limitation of our study was that it did not include hypothyroid patients with malabsorption, where liquid LT4 seems to be superior to tablets. However, the present study was conducted in order to establish the equivalence of the $\mathrm{T} 4{ }^{\circledR}$ drops formulation to $\mathrm{T} 4{ }^{\circledR}$ tablets and to obtain approval by the Greek National Organization for Medicines for use in hypothyroid patients. Therefore, $\mathrm{T} 4^{\circledR}$ drops could not be tested in hypothyroid patients with malabsorption. A possible weakness of the $\mathrm{T} 4{ }^{\circledR}$ drops formulation lies in the complexity of self-administering the correct dose that has negatively impacted the adherence of some patients. The manufacturer was informed and they will probably make adjustments to improve the dosimetric device when the product is released to the market. Finally, although the price of this new preparation is not known at the moment, it would not differ substantially from that of LT4 tablets.

In conclusion, the new liquid formulation of $\mathrm{T} 4^{\circledR}$ drops is therapeutically equivalent to the classic $\mathrm{T} 4{ }^{\circledR}$ tablet preparation of the same manufacturer, as assessed by the similar serum TSH levels achieved by either substitution therapy in adult hypothyroid patients without known malabsorption. 


\section{Statement of Ethics}

The study protocol was approved by the University Hospital of Patras Ethics Committee and by the Greek National Organization for Medicines. Each participant was informed regarding the procedures of study participation and signed a witnessed, written informed consent form.

\section{Funding Sources}

This study was supported by Uni-Pharma S.A., Greece. UniPharma provided the liquid and tablet LT4 formulations administered to the participants and covered the cost of the hormone measurements performed.

\section{Author Contributions}

\section{Disclosure Statement}

The authors have no conflicts of interest to declare.
G.K.M.: data collection, statistical analysis, and manuscript writing. K.D.: data collection. I.M.: hormone measurements. I.T.: study design. G.S.: statistical analysis. K.B.M. and M.A.M.: study design and manuscript writing.

\section{References}

1 Taylor PN, Albrecht D, Scholz A, GutierrezBuey G, Lazarus JH, Dayan CM, et al. Global epidemiology of hyperthyroidism and hypothyroidism. Nat Rev Endocrinol. 2018 May; 14(5):301-16

2 Jonklaas J, Bianco AC, Bauer AJ, Burman KD, Cappola AR, Celi FS, et al.; American Thyroid Association Task Force on Thyroid Hormone Replacement. Guidelines for the treatment of hypothyroidism: prepared by the American Thyroid Association Task Force on Thyroid Hormone Replacement. Thyroid. 2014 Dec; 24(12):1670-751.

3 Blakesley V, Awni W, Locke C, Ludden T, Granneman GR, Braverman LE. Are bioequivalence studies of levothyroxine sodium formulations in euthyroid volunteers reliable? Thyroid. 2004 Mar;14(3):191-200.

4 Roti E, Minelli R, Gardini E, Braverman LE. The use and misuse of thyroid hormone. Endocr Rev. 1993 Aug;14(4):401-23.

5 Skelin M, Lucijanić T, Amidžić Klarić D, Rešić A, Bakula M, Liberati-Čizmek AM, et al. Factors Affecting Gastrointestinal Absorption of Levothyroxine: A Review. Clin Ther. 2017 Feb;39(2):378-403.

6 Benvenga S, Di Bari F, Vita R. Undertreated hypothyroidism due to calcium or iron supplementation corrected by oral liquid levothyroxine. Endocrine. 2017 Apr;56(1):13845.

7 Vita R, Di Bari F, Benvenga S. Oral liquid levothyroxine solves the problem of tablet levothyroxine malabsorption due to concomitant intake of multiple drugs. Expert Opin Drug Deliv. 2017 Apr;14(4):467-72.

8 Garber JR, Cobin RH, Gharib H, Hennessey JV, Klein I, Mechanick JI, et al.; American Association Of Clinical Endocrinologists And American Thyroid Association Taskforce On Hypothyroidism In Adults. Clinical practice guidelines for hypothyroidism in adults: cosponsored by the American Association of Clinical Endocrinologists and the American Thyroid Association. Thyroid. 2012 Dec; 22(12):1200-35.

9 Markou KB, Koukkou EG. The Greek population is iodine sufficient and not at risk of io- dine-induced hyperthyroidism. J Nutr. 2012 Aug;142(8):1611.

10 Gkotsina M, Michalaki M, Mamali I, Markantes G, Sakellaropoulos GC, Kalfarentzos F, et al. Improved levothyroxine pharmacokinetics after bariatric surgery. Thyroid. 2013 Apr;23(4):414-9.

11 Singer PA, Cooper DS, Levy EG, Ladenson PW, Braverman LE, Daniels G, et al. Treatment guidelines for patients with hyperthyroidism and hypothyroidism. Standards of Care Committee, American Thyroid Association. JAMA. 1995 Mar;273(10):808-12.

12 Fallahi P, Ferrari SM, Antonelli A. In Patients With Subclinical Hypothyroidism While In Therapy With Tablet L-T4, The Liquid L-T4 Formulation Is More Effective In Restoring Euthyroidism. Endocr Pract. 2017 Feb;23(2): 170-4.

13 Guglielmi R, Grimaldi F, Negro R, Frasoldati A, Misischi I, Graziano F, et al. Shift from Levothyroxine Tablets to Liquid Formulation at Breakfast Improves Quality of Life of Hypothyroid Patients. Endocr Metab Immune Disord Drug Targets. 2018;18(3):235-40.

14 Marina M, Ceda GP, Aloe R, Gnocchi C, Ceresini G. Circulating concentrations of free thyroxine after an oral intake of liquid LT4 taken either during fasting conditions or at breakfast. Acta Biomed. 2016 Jan;87(3):24752.

15 Benvenga S, Capodicasa G, Perelli S. l-Thyroxine in an Oral Liquid or Softgel Formulation Ensures More Normal Serum Levels of Free T4 in Patients with Central Hypothyroidism. Front Endocrinol (Lausanne). 2017 Nov; $8: 321$.

16 Lombardi CP, Bocale R, Barini A, Barini A, D'Amore A, Boscherini M, et al. Comparative study between the effects of replacement therapy with liquid and tablet formulations of levothyroxine on mood states, self-perceived psychological well-being and thyroid hormone profile in recently thyroidectomized patients. Endocrine. 2017 Jan;55(1):51-9.

17 Peterson SJ, McAninch EA, Bianco AC. Is a Normal TSH Synonymous With "Euthyroidism" in Levothyroxine Monotherapy? J Clin
Endocrinol Metab. 2016 Dec;101(12):496473.

18 Eisenberg M, Distefano JJ 3rd. TSH-based protocol, tablet instability, and absorption effects on L-T4 bioequivalence. Thyroid. 2009 Feb;19(2):103-10.

19 Jameson LJ. Harrison's Endocrinology. 4th ed. New York: McGraw-Hill Press; 2016.

20 Hadlow NC, Rothacker KM, Wardrop R, Brown SJ, Lim EM, Walsh JP. The relationship between TSH and free $\mathrm{T}_{4}$ in a large population is complex and nonlinear and differs by age and sex. J Clin Endocrinol Metab. 2013 Jul;98(7):2936-43.

21 Rothacker KM, Brown SJ, Hadlow NC, Wardrop R, Walsh JP. Reconciling the Log-Linear and Non-Log-Linear Nature of the TSH-Free T4 Relationship: Intra-Individual Analysis of a Large Population. J Clin Endocrinol Metab. 2016 Mar;101(3):1151-8.

22 Fitzgerald SP, Bean NG. The Relationship between Population T4/TSH Set Point Data and T4/TSH Physiology. J Thyroid Res. 2016; 2016:6351473.

23 McNally LJ, Ofiaeli CI, Oyibo SO. Treatmentrefractory hypothyroidism. BMJ. 2019 Feb; 364:1579.

24 Virili C, Giovanella L, Fallahi P, Antonelli A, Santaguida MG, Centanni M, et al. Levothyroxine Therapy: Changes of TSH Levels by Switching Patients from Tablet to Liquid Formulation. A Systematic Review and Meta-Analysis. Front Endocrinol (Lausanne). 2018 Jan;9:10.

25 Bellastella G, Caputo M, Maiorino MI, Longo M, Scappaticcio L, Giugliano D, et al. EMPATHY: A New Tool for Identifying the Most Suitable Thyroxine Formulation in Hypothyroid Patients. Thyroid. 2019 Jul;29(7):928-33.

26 Vita R, Fallahi P, Antonelli A, Benvenga S. The administration of L-thyroxine as soft gel capsule or liquid solution. Expert Opin Drug Deliv. 2014 Jul;11(7):1103-11.

27 Cassio A, Monti S, Rizzello A, Bettocchi I, Baronio F, D'Addabbo G, et al. Comparison between liquid and tablet formulations of levothyroxine in the initial treatment of congenital hypothyroidism. J Pediatr. 2013 Jun; 162(6):1264-9. 